12.

\title{
POJMOVNA METAFORA \\ I KONCEPTUALIZACIJA SMRTI \\ U PROLJEĆIMA IVANA GALEBA \\ VLADANA DESNICE
}

\section{Virna Karlić}

UDK: 821.163.42-311.1Desnica, V. :612.013

Prethodno priopćenje

Sažetak: Autorica se bavi analizom pojmovne (konceptualne) metafore smrti u romanu Proljeća Ivana Galeba Vladana Desnice. Rad se otvara kratkim pregledom književnih i lingvističkih teorija metafore, s posebnim osvrtom na kognitivistički pristup metafori kao mentalnom mehanizmu s pomoću kojeg čovjek poima i organizira stvarnost, a koji se odražava u jeziku. Nadalje slijedi prikaz najfrekventnijih konvencionalnih pojmovnih metafora smrti u svakodnevnoj jezičnoj upotrebi, koje se potom uspoređuju s metaforama smrti u Proljećima Ivana Galeba. U završnom poglavlju raspravlja se o rezultatima provedenog istraživanja te se otvara pitanje funkcija koje utvrđene metafore smrti vrše u Desničinu romanu.

Ključne riječi: poetska metafora, pojmovna metafora, konceptualna analiza, Vladan Desnica, Proljeća Ivana Galeba

od pretpostavkom da čovjek konceptualizira svijet oko sebe (uspostavlja pojmove) na temelju svojeg fizičkog, osjetilnog, emocionalnog i intelektualnog iskustva, teorija pojmovne ili konceptualne metafore zasniva se na hipotezi da jednostavne i konkretne pojave iz svijeta koji nas okružuje doživljavamo izravno, a one apstraktne i složene posredstvom poznatih, bazičnih iskustava. Utoliko kognitivna semantika značenje definira kao subjektivnu konceptualizaciju stvarnosti, a jezik smatra ključnim pokazateljem načina na koji razmišljamo (,jezik je prozor u ljudski um“). Dok se u okviru teorije književnosti metafora promatra kao stilska figura, u okviru kognitivne semantike ona se tumači kao mentalni mehanizam s pomoću kojeg čovjek poima i organizira stvarnost. Ovaj rad bavi se pitanjem kako je konceptualiziran kompleksan i apstraktan pojam smrti u Proljećima Ivana Galeba Vladana Desnice, romanu u kojemu je smrt jedan od središnjih motiva. Rezultati se analize potom uspoređuju s rezultatima istraživanja pojmovne metafore smrti u svakodnevnom, nepoetskom jeziku. Pritom se otvara pitanje odnosa i granica između leksičke (nepoetske) metafore i metafore kao tropa (poetske), kao i pitanje odnosa i granice 
između nepoetskog i poetskog jezika. Analiza se zasniva na pretpostavci da će utvrđivanje modela pripovjedačeve konceptualizacije smrti u Proljećima Ivana Galeba pridonijeti interpretaciji romana, posebice na planu razumijevanja strategija oblikovanja njegova glavnog lika (ujedno i pripovjedača).

\section{Metafora u KNJiŽEVnOsti i IZVAN NJE: PRISTUPI I TUMAČENJA}

Pristupi metafori brojni su i raznoliki, a iz njih proizlaze njezine različite definicije i tumačenja. Metafora je jedan od središnjih pojmova suvremene književne teorije, a u novije vrijeme i lingvistike, filozofije, psihologije, teologije, sociologije i drugih znanosti. ${ }^{1}$ Iako se o njoj najčešće razmišlja kao o stilskoj figuri, ${ }^{2}$ postoje još dvije njezine razine - pojmovna i leksička. ${ }^{3}$ Metafora se kao trop uglavnom definira kao „prijenos značenja jedne riječi na drugu“, ${ }^{4}$ odnosno kao „zamjenjivanje jedne riječi drugom prema značenjskoj srodnosti ili analogiji“.5 Njezino je uspostavljanje moguće zahvaljujući pojmovnoj metafori kao mehanizmu mišljenja koji omogućava da apstraktne i složene pojave doživljavamo posredno, konkretiziranjem i pojednostavnjivanjem, odnosno svođenjem na poznato iskustvo. Tako se u navedenom primjeru iz Desničina romana Proljeća Ivana Galeba upotreba glagola prezati zasniva na pojmovnoj metafori SMRT je žIVO BIĆE:

Smrt preza pred vedrim djetinjim okom (...) (40)

Leksička (nepoetska) metafora također je odraz pojmovne metafore u jeziku, a podrazumijeva ustaljen prijenos naziva s jednog pojma na drugi na temelju njihovih sličnosti (npr. ustaljen prijenos na kojem se temelji metaforički izraz gledati smrti $u$ oči također se zasniva na pojmovnoj metafori SMRT je ŽIVO BIĆE).

Prema podjeli Elene Semino i Gerarda Steena, ${ }^{7}$ teorijski pristupi metafori dijele se na dvije skupine: (1) teorije koje naglašavaju razlike između leksičke (nepoetske) metafore i metafore kao tropa $\left(\right.$ poetske) ${ }^{8}$ te (2) teorije koje ukazuju na njihovu međusobnu povezanost i uvjetovanost.

Prva skupina okuplja teorije različitih tradicija (od formalističke škole, preko angloameričke stilistike do kognitivne poetike) koje povezuje zajednička pretpostavka da metafora

\footnotetext{
Vladimir Bıтı, Pojmovnik suvremene književne teorije, Zagreb 1997., 221.

2 „Još od antike metafora se promatra kao najsnažnija i najčešća figura, kao kraljica figura.“ Usp. Krešimir BAGić, Rječnik stilskih figura, Zagreb 2012., 187.

3 Rajna DragićEvić, Leksikologija srpskog jezika, Beograd 2007., 147.

4 Milivoj Solar, Teorija književnosti sa rječnikom književnoga nazivlja, Beograd 2012., 412.

5 K. BAGIĆ, Rječnik stilskih figura, 187.

6 Svi primjeri iz romana pretraženi su i preuzeti iz elektroničkog izdanja: Vladan Desnica, Proljeća Ivana Galeba, Beograd 2010. (https://gimnazijadg.files.wordpress.com/2012/04/vladan-desnica-proljeca-ivana-galeba.pdf). Usto se koristilo i tiskano izdanje: Vladan Desnica, Proljeća Ivana Galeba, Varaždin 2005.

7 Elena Semino - Gerard STEen, „Metaphor in Literature“, The Cambridge handbook of metaphor and thought, Cambridge 2008., 232-246.

8 Autori se u studiji izvorno koriste terminima poetska i nepoetska metafora u smislu pripadanja poetskome ili nepoetskome jeziku (jeziku književnosti).
} 
nije isključivo književni fenomen, ali da je odnos između metafore u književnosti i one izvan nje diskontinuiran. Glavni je cilj pristupa ove skupine odrediti upotrebu, obilježja i funkcije metafora u pojedinim književnim tekstovima, žanrovima ili autorskim opusima. Naglasak se pritom stavlja na jedinstvenost pojedinačnih primjera metafore u književnim djelima. Predstavnici ove struje leksičku (nepoetsku) metaforu vide kao mrtvu, a time i manje vrijednu od metafore kao tropa (poetske).

Osamdesetih godina prošlog stoljeća nastupa velik obrat na planu proučavanja metafore. Najednom „mrtve“, leksičke ili nepoetske metafore počinju igrati središnju ulogu u razvoju kognitivne teorije metafore Georgea Lakoffa i njegovih kolega i sljedbenika (Raymond Gibbs, Mark Johnson, Mark Turner i drugi). Ta je teorija donijela novi pogled na uloge metafore u svakodnevnoj komunikaciji i bacila drugačije svjetlo na metaforu kao trop. Lakoff i Turner iznose stav da je metafora kao stilska figura u književnim djelima kreativna realizacija konvencionalne pojmovne metafore. Predstavnici ovoga pristupa metaforu u svakodnevnom jeziku vide kao primarnu, a metaforu u književnosti kao kreativnu izvedenicu ustaljenih, leksičkih metafora.?

Navedeni su pristupi metafori u mnogočemu različiti i nepomirljivi, međutim, umnogome su i komplementarni jer se usmjeravaju na njezine različite aspekte. Dok se predstavnici prve skupine teorijskih pristupa fokusiraju na ulogu specifičnih metaforičkih obrazaca u pojedinim djelima, opusima autora ili žanrovima (idiografski pristup), predstavnici one druge ne bave se pojedinačnim primjerima, već općim obilježjima pojmovne metafore. Iako se proučavatelji metafore (neovisno o pristupu i teorijskoj podlozi) načelno slažu s time da su metafore u književnosti kreativnije i inovativnije od onih izvan nje, tu je tvrdnju teško empirijski dokazati. Ključan problem predstavlja škakljivo pitanje granice između poetskog i nepoetskog jezika, kao i činjenica da jezik književnosti varira na brojnim razinama, ovisno o vrsti i žanru književnog djela. Dosad provedena kvantitativna istraživanja o toj temi potvrđuju pretpostavku da je poetski jezik više metaforičan nego nepoetski, a da je poezija bogatija metaforikom od proze. Osim toga, novije lingvističke (diskurzivne i korpusne) studije pokazuju da kreativna upotreba metafora nije ograničena samo na književnost te otvaraju pitanje karakteristika, okidača i funkcija metaforičke kreativnosti u diskursu. ${ }^{10}$

\section{Metafora u OČima KOGNitivne ZNANOSTI}

Dok tradicionalni književni pristupi metaforičnosti prilaze prvenstveno kao jednoj od temeljnih značajki jezika književnosti, suvremeni lingvistički pristupi rasvjetljavaju i inzistiraju na činjenici da i svakodnevni jezik obiluje metaforičkim izrazima te da metafora nije samo ukras u pjesničkom jeziku, nego način svakodnevnog izražavanja. U okviru kognitivne lingvistike, jedne od grana kognitivne znanosti, ${ }^{11}$ metafora se promatra kao

9 Usp. George Lakoff - Mark Turner, More Than Cool Reason: A Field Guide to Poetic Metaphor, Chicago 1989. Valja naglasiti kako ovaj pristup zanemaruje inovativne metafore koje se ne mogu povezati s konvencionalnim pojmovnim metaforama.

10 Za kratak pregled spomenutih istraživanja usp. E. Semino - G. STEen, „Metaphor in Literature“.

11 Sedamdesetih godina 20. stoljeća kognitivna znanost počinje se profilirati kao zasebno znanstveno područje te kao nova akademska disciplina koja se bavi proučavanjem uma i inteligencije. Kognitivna znanost veliko je polje i 
način ustroja znanja i konceptualizacije svijeta koji nas okružuje. U kognitivnoj se lingvistici jezik smatra odrazom ljudskog uma i spoznajnih procesa, a značenje se poistovjećuje s konceptualizacijom - „obrazovanjem pojmova na osnovu čovekovog fizičkog, čulnog, emocionalnog i intelektualnog iskustva o svetu koji ga okružuje“. ${ }^{12}$ U tom je smislu značenjska struktura jezika po svojoj prirodi subjektivna te odražava i razotkriva razne aspekte ljudske kognicije:

Konceptualnoj metafori prilazimo kao jednom od kognitivnih procesa koji se zrcale u jeziku. Jeziku također pristupamo kao spoznajnoj pojavi - leksik i gramatiku smatramo motiviranim konstrukcijama simboličke naravi. Dakle, jezik smatramo neodvojivo vezanim za naš um. Temeljna je značajka jezika da je on vezan uz nas kao ljude pa se u njemu odražava naša spoznajnost, naša tjelesnost, naša društvenost. Baš je takva i konceptualna metafora - ona je tjelesna, neurološka, spoznajna, jezična (konstrukcijska), komunikacijska, kulturološka. ${ }^{13}$

Tradicionalnu definiciju metafore kao poetske figure koja podrazumijeva prijenos imena s jednog pojma na drugi Lakoff i Johnson nadograđuju u svojem kapitalnom djelu Metafore koje život znače ${ }^{14} \mathrm{u}$ kojem ističu kako esencija metafore leži u razumijevanju i proživljavanju jednog pojma putem drugog. Time se tumačenje metafore kao tropa proširuje na njezino razumijevanje kao mentalnog mehanizma koji se zasniva na preslikavanju strukture jednog pojma ili domene na drugi pojam ili domenu. ${ }^{15}$ Pritom se prijenos odvija u smjeru od konkretnog, lakše pojmljivog (npr. ljudsko tijelo, životinje, biljke, svjetlost/tama, toplo/ hladno) prema apstraktnom (npr. emocije, mišljenje, ljudski odnosi, vrijeme, smrt):

Taknula me njegova ljubaznost i obazrivost, koju redovno ne možemo tražiti od ljudi sviklih da po svom zvanju vječito gledaju ljudskoj patnji i smrti licem u lice. (26)

Tako se u navedenom primjeru iz Desničina romana apstraktni pojmovi patnja i smrt konceptualiziraju posredstvom konkretne domene živog bića (PATNJA/SMRT je žIVO BIĆE) njihovim poimanjem kao stvorenja s kojima se možemo gledati licem u lice.

Prema klasifikaciji Lakoffa i Johnsona ${ }^{16}$ pojmovne se metafore dijele na tri temeljne skupine: (1) strukturne - jedan se pojam metaforički strukturira s pomoću drugog (npr. izraz počivati u miru odražava strukturnu pojmovnu metaforu SMRT je SPAVANJE); (2) orijentacijske - metafore koje se zasnivaju na prostornoj orijentaciji; čije su izvorne domene prostorni odnosi (npr. izraz pasti u grob odražava pojmovnu metaforu SMRT je DOLJE); (3) ontološke - metafore koje se zasnivaju na razumijevanju apstraktnih pojmova poput emocija ili ideja posredstvom entiteta ili situacija (npr. već spomenut izraz gledati se sa smrću licem u lice). Budući da se često zasnivaju na svim ljudima zajedničkim iskustvima, pojmovne su metafore nerijetko univerzalne, međutim, zbog kulturalnih specifičnosti i različitog fizičkog

pokriva širok spektar tema o kogniciji, a podrazumijeva interdisciplinarno proučavanje koje povezuje razna relevantna znanstvena područja poput psihologije, psihijatrije, neuroznanosti, lingvistike, antropologije, biologije i dr.

12 R. DragićEvić, Leksikologija srpskog jezika, 90.

13 Mateusz-Milan Stanojević, Konceptualna metafora. Temeljni pojmovi, teorijski pristupi i metode, Zagreb $2013 ., 15$.

14 George Lakoff - Mark Johnson, Metaphors we live by, Chicago 1980. Hrvatski prijevod knjige, objavljen 2015. godine, nosi naslov Metafore koje život znače (prev. Anera Ryznar).

15 Usp. R. DragiĆević, Leksikologija srpskog jezika.

16 Usp. G. Lakoff - M. Johnson, Metaphors we live by. 
okruženja one mogu biti i jezično specifične (npr. izrazi predati duh Gospodu, otići na posljednji sud, otići na bolje mjesto zasnivaju se na vjerovanjima u judeo-kršćanskoj tradiciji).

Pojmovne metafore mogu biti dio ustaljenog jezičnog znanja (konvencionalna metafora) ili se mogu konstruirati u diskursu - kako književnom tako i neknjiževnom (inovativna metafora). Prema tradicionalnim podjelama, metafore se dijele na žive i mrtve, dok konceptualna teorija ne vjeruje u „mrtvilo“ mrtvih metafora te ih radije naziva „uspavanima“. ${ }^{17}$ Pritom žive metafore podrazumijevaju metafore koje iznenađuju i za koje nema puno potvrda u korpusu te su teško razumljive izvan konteksta i bez dodatnog objašnjenja. Mrtve ili „uspavane“ metafore ustaljene su i govornici često nisu svjesni metaforičnosti takvih izraza (npr. grlo žarulje, planinski lanac). U analizi romana Proljeća Ivana Galeba obuhvaćene su sve metafore s ciljnom domenom SMRT, bez obzira na njihovu vrstu i stupanj ustaljenosti.

\section{Metafore kOJE SMRT ZnaČE}

(Pojmovna) metafora smrti u književnim djelima i drugim oblicima jezične produkcije predmet je brojnih istraživanja. ${ }^{18}$ Za potrebe ovoga rada posebno se korisnom pokazala studija Juane I. Marin-Arrese, u kojoj su popisane i uspoređene najučestalije konvencionalne pojmovne metafore smrti i umiranja u svakodnevnom španjolskom i engleskom jeziku. ${ }^{19}$ U nedostatku istraživanja konvencionalne pojmovne metafore smrti u hrvatskom ili srpskom jeziku, studija Marin-Aresse smatrala se zadovoljavajućim izvorom i polazištem za analizu upravo zbog već spomenute činjenice da se pojmovne metafore uglavnom zasnivaju na općim ljudskim iskustvima te su stoga nerijetko univerzalne. Zbog kulturne bliskosti među govornicima španjolskog, engleskog te slavenskih jezika, nisu očekivane značajne jezične specifičnosti na planu konceptualizacije smrti. Analiza rezultata ove studije takva je očekivanja potvrdila jer su njezini rezultati umnogome podudarni sa stanjem u hrvatskom i srpskom jeziku. Zato u nastavku slijedi prikaz autoričine podjele najzastupljenijih pojmovnih metafora smrti na pet glavnih skupina s obzirom na tip izvorne domene. Podjela je popraćena primjerima iz hrvatskoga jezika. ${ }^{20}$

(1) Fizički efekti smrti. Primjerice, vrlo je raširena pojmovna metafora SMRT je sPAVAnje, koja se zasniva na sličnostima između osobe koja spava i koja je mrtva (obje leže i mirne su). Ta se eufemistička metafora ostvaruje u ustaljenim izrazima i frazemima kao što su počivati u miru, vječni počinak, posljednje počivalište, smrtna postelja, spavati vječnim

17 M. Stanojević, Konceptualna metafora, 90.

18 Ovdje ćemo navesti tek nekoliko takvih primjera: Zenaida Meco, „Konceptualna analiza smrti na primjeru pjesme Modra rijeka Maka Dizdara“, Zbornik pedagoškog fakulteta u Zenici, 6/2008., 261-267; Elena FAUR, The Metaphors for Death and the Death of Conceptual Metaphors in Poetry. An Analysis Based on Emily Dickinson's Poem „Because I Could Not Stop For Death“ (http://www.dacoromania.inst-puscariu.ro); Cristina Flores Moreno, „Time, Life and Death Metaphors in Shakespeare's Sonnets: The Lakoffian Approach to Poetic Metaphors“, RESLA 13/1998. - 1999., 287-304; Eliecer Crespo FernandÉz, „The Language of Death: Euphemism and Conceptual Metaphorization in Victorian Obituaries", SKY Journal of Linguistics, 19/2006., 101-130.

19 Juane I. Marin-Arrese, „To Die, to Sleep: A Contrastive Study of Metaphors for Death and Dying in English and Spanish“, Language Sciences, 18/1996., br. 1-2,37-52.

20 Većina primjera frazema preuzeta je iz rada: Maja OpAšrć - Maja Gregorović, „Smrt u hrvatskoj frazeologiji“, Croatica et Slavica Iadertina, 6/2010., 55-72. 
snom, usnuti vječni mir itd. Ovakav značenjski prijenos motiviran je čovjekovom težnjom za pojašnjenjem onoga najnepoznatijega onim najpoznatijim: ljudskim tijelom, općenito njegovim okruženjem. ${ }^{21}$

Projekcije ili proširenja značenja zasnivaju se na metonimiji - procesu prijenosa reference, to jest referiranju na jednu istaknutu karakteristiku koja predstavlja cijelu značenjsku domenu. Tako u navedenim izrazima pojedini fiziološki efekti smrti predstavljaju umiranje: izdahnuti, sklopiti oči (zauvijek), otegnuti papke, obladiti pete i slično, što je slučaj i s aspektima pokapanja ili raspadanja tijela u izrazima: završiti pod zemljom, biti hrana crvima, postati prah i prašina, pretvoriti se u prah (pepeo).

(2) Personifikacija. Pridavanje ljudskih obilježja apstraktnim pojmovima vrlo je česta pojava. Tako u mnogim jezicima smrt dolazi po nekoga, odvodi galje ili zatječe; ljudi bivaju $u$ raljama smrti, bore se sa smrću ili gledaju smrti u oči. ${ }^{22}$

(3) Religija i sustav vjerovanja. U svim slavenskim jezicima postoji cijeli niz izraza za smrt utemeljenih na vjerovanjima u judeo-kršćanskoj tradiciji (vjerovanje u život poslije smrti, vjerovanje da se raj nalazi na nebesima, da je smrt trenutak posljednjeg suda i tome slično). Otuda potječu pojmovne metafore i na njima zasnovani izrazi: vječni život, sjediniti se s Bogom, otići na posljednji sud, otići na bolje mjesto, otići na nebo, dati/predati dušu Bogu/Gospodu, ispustiti dušulduh.

(4) Druga sociokulturna vjerovanja i prakse također bivaju osnovom za određene pojmovne metafore smrti. Takve su, primjerice, pojmovne metafore proizašle iz nasilnih praksi koje uzrokuju smrt: platiti krvlju/glavom, zamastiti konopac/kolac.

(5) Prostorni i vremenski odnosi. Pojmovne se metafore smrti često zasnivaju na spacijalnim izvornim domenama kao što su, primjerice, žIVOT NA ZEMLJI je OMEĐEN PROSTOR (napustiti ovaj svijet, biti između života i smrti); SMRT je ODLAZAK (izrazi za smrt s glagolima otići, napustiti, rastati se); SMRT je DOLJE (biti ispod zemlje, leći/pasti/sići u grob). Isto je slučaj $s$ vremenskim odnosima, pa se tako, primjerice, na pojmovnoj metafori SMRT je POSLJEDNJi ČAs zasnivaju izrazi: vrijeme mu/joj je isteklo, došao je čas, odbrojeni su mul joj dani, kucnuo muljoj je čas/ura.

Predstavljena tipologija najučestalijih konvencionalnih pojmovnih metafora smrti u analiziranim jezicima otkriva sklonost njihovih izvornih govornika upotrebi eufemističkih metaforičkih izraza za smrt i umiranje. Jedan od uzroka nastajanja metafora skriva se upravo u tabuističkom ponašanju, koje se očituje u preimenovanju stanovitih smislova i njima pripadajućih designata. ${ }^{23}$

21 Ante Stamać, Teorija metafore, Zagreb 1983., 68.

22 Ovdje valja naglasiti da se u retorici i stilistici personifikacija promatra kao zasebna, „kompleksna stilska figura koja se od prigode do prigode realizira pomoću metafore, sinegdohe i metonimije“, a definira se kao „pridavanje ljudskih osobina, misli, osjećaja i ponašanja kakvu predmetu, stvari, pojavi, apstrakciji, biljci ili životinji; oljuđivanje“. Usp. K. BAGIĆ, Rječnik stilskih figura, 245. Iz perspektive teorije pojmovne metafore, pa tako i u studiji autorice MarinAresse, personifikacija se promatra kao vrsta metafore. Inače, antropomorfno poimanje svijeta smatra se jednim od temeljnih uzroka nastajanja metafore jer se na temelju njega „smislovima pojava u prirodi odnosno u duhovnoj sferi pridijevaju imena što pripadaju stvarnosti čovjekova tijela i duha“. Usp. A. Stamać, Teorija metafore, 67.

23 Isto, 74. 


\section{Pojmovna metafora smrti u romanu PROLJEĆA IVANA GALEBA}

U ovome poglavlju rada prikazuju se rezultati provedene analize metafora s ciljnom domenom smrti u Proljećima Ivana Galeba Vladana Desnice. Analizom se željelo utvrditi koji tip metafora prevladava u romanu, posebice stoga što je smrt jedan od njegovih centralnih motiva, a riječ je o proznom djelu. ${ }^{24}$ Nadalje, željelo se utvrditi koje su najzastupljenije izvorne domene pojmovnih metafora smrti u romanu te usporediti rezultate analize s prethodno predstavljenim popisom najučestalijih konvencionalnih pojmovnih metafora u svakodnevnoj jezičnoj upotrebi. U konačnici je cilj uvidjeti kako rezultati ovakvog tipa (lingvističke) analize mogu pridonijeti tumačenju romana.

Leksem 'smrt' u romanu eksplicitno se pojavljuje dvjestotinjak puta. Na temelju pretrage metaforičkih izraza prema ciljnoj domeni zabilježeno je šezdeset poetskih metafora smrti zasnovanih na pojmovnim metaforama koje se mogu svrstati u tri temeljne skupine $s$ obzirom na izvoru domenu.

\section{(I) Personifikacija}

Čak trećina zabilježenih metaforičkih izraza u romanu zasniva se na pojmovnoj metafori SMRT je ŽIVO BIĆE, što najavljuje i sâm podnaslov romana Igre proljeća i smrti. Metaforički izrazi ove skupine dijele se nadalje na potkategorije.

(1a) smrt kao ljudsko biće:

Za njenim prolaskom [smrti], kud je ona pomela svojim crnim skutom, ostaje vir praznine (...) (26)

Smrt je tačno našeg stasa i uzrasta (...) (60)

(...) imam iluziju da smrt ne može da stavi ruku na moje rame. (132)

Vjerovatno postoji neki istočnjački mit ili legenda (...) o čovjeku koga je smrt mogla da zaskoči samo na spavanju, samo dok miruje. (132)

Ovdje se kao posebna podskupina izdvajaju izrazi u kojima smrt predstavlja neprijatelja:

Trebat će sve drugo ostaviti kraju i poduhvatiti se, udruženim snagama, u jedan veliki, vrhovni napor da se ona [smrt] pobijedi, da se prevlada. (59)

Svi naši napori, sva naša djela samo su vidovi borbe protiv smrti. (61)

Veliki su osjećaji jedan oblik borbe protiv smrti (...) (223)

(1b) smrt kao životinja ili biljka:

Smrt preza pred vedrim djetinjim okom. (40)

$\overline{24}$ Do sada se znatno veća pozornost posvećivala metafori kao tropu (u novije vrijeme i pojmovnoj metafori) u poeziji. 
Smrt se začinje i gnijezdi u ustajalim klimama jučerašnjice. (242)

Gledao sam je kao šupalj dud, ulište klica smrti. (40)

(1c) smrt kao živi entitet koji nastanjuje ljudsko biće (pritom je biće konceptualizirano posredstvom pojmovne metafore DUŠA/TIJELO je OMEĐEN PROSTOR):

Negdje duboko zapretana u djetinjem biću leži jedna ćelija u kojoj tinja besmrtnost. A odmah do nje, u neposrednom susjedstvu, druga ćelija u kojoj drijema smrt. One žive u dobrim susjedskim odnosima. (40)

Grud mu je puna ljeskanja bića i nebića, u njoj se motaju smrt i besmrtnost, sad uhvaćene u koštac, sad obujmljene u zagrljaj. (63)

Gledao sam kako se u njoj nose mladost i smrt. (132)

\section{(2) Primarne metafore}

Druge po zastupljenosti u romanu, pojmovne metafore, utemeljene su na utjelovljenim vezama, zasnovane na ljudskim osjetilima: ${ }^{25}$ SMRT je TAMNA, SMRT je HLADNA, a vezano uz aspekt raspadanja tijela, pojavljuju se metaforički izrazi u kojima smrt predstavlja izvor mirisa.

(2a) smrt je tamna:

U oblačne dane, u dane smrti (...) (41)

Veliki su osjećaji jedan oblik borbe protiv smrti, krhki mostovi između konačnog i beskonačnoga što presvođuju bezdane mraka. (223)

(...) život - to je tvoja „ideja“; a smrt, naličje, tamna strana tog žetona, kojim se poigravaš (248)

(2b) smrt je hladna:

Dijete je ne prepoznaje, još joj ne zna imena ni slova, ali već se ježi od njezina hlada. (40) (...) dijete joj [smrti] ne zna imena ni slave, ali u oblačne i besunčane dane osjeća na licu hladan dah vjetra za njenim prolaskom. (40)

(2c) smrt kao izvor mirisa:

(...) mirisi jelâ, kućevnosti, ishlapljela naftalina već čudno udaraju mirisom smrti. (177) Kao da je mirisala smrt (...) (235)

25 Upravo je intersenzorno percipiranje jedan od glavnih uzroka nastanka metafore - „ovaj tip uzroka širi ljestvicu percipiranja na slušno, dodirno, okusno pa i njušno polje, ukoliko se ta polja osjetilnosti mogu izraziti govorno, tj. jezičnim znakovima.“A. Stamać, Teorija metafore, 73. 


\section{(3) Prostorni odnosi}

U romanu se na više mjesta pojavljuje orijentacijska metafora SMRT je DOLJE:

\section{Jedno je izložiti se zalutalom tanetu, (...) pasti prosvirana šešira (177)}

Pojavljuje se i konvencionalna spacijalna metafora SMRT je OMEĐEN PROSTOR, koja se odražava u izboru prijedloga 'u' uz imenicu 'smrt' u akuzativu ili lokativu:

odlazi se $\mathbf{u}$ smrt (65)

pričanja o devojci na odru, (...) poljepšanoj u smrti kao Trnoružica (106)

Uz navedene tri najzastupljenije skupine metafora, u romanu važnu ulogu imaju i pojmovne metafore SMRT je PREDMET (smrt pripada samo stvaraocu, str. 61), SMRT je BOLEST (lijek od smrti, str. 184) te SMRT je KRAJ (Idealan završetak, kakav se samo poželjeti može, str. 174).

\section{ZAKLJUČCI: OBILJEŽJA I FUNKCIJE METAFORE U ROMANU}

Analiza Proljeća Ivana Galeba pokazala je da roman obiluje metaforama smrti, koje se s obzirom na izvornu domenu mogu svrstati u tri skupine - personifikacije te primarne i prostorne metafore. U skladu s očekivanjima, ${ }^{26}$ pokazalo se da su gotovo svi zabilježeni primjeri inovativnih metafora u romanu kreativne izvedenice uobičajenih, konvencionalnih pojmovnih metafora. O tome svjedoče podudarnosti između pojmovnih metafora smrti na kojima se zasnivaju najučestaliji metaforički izrazi u nepoetskom jeziku ${ }^{27}$ i pojmovnih metafora iz kojih proizlaze metafore smrti u romanu. Međutim, uočljiva su i neka odstupanja i specifičnosti - primjerice, u potpunosti izostaju konvencionalne pojmovne metafore zasnovane na kršćanskim vjerovanjima te na fizičkim efektima smrti (npr. SMRT je SPAVA$\mathrm{NJE}^{28}$ ), koje su u svakodnevnoj komunikaciji vrlo učestale.

Kako ovakvi podaci mogu pridonijeti interpretaciji književnog djela? Pretpostavka da su (pojmovne) metafore „prozor u ljudski um“ povlači za sobom ideju da im se u kontekstu analize Proljeća može pristupiti kao „prozoru“ u um Ivana Galeba, odnosno da se mogu tumačiti kao jedno od sredstava koje autor primjenjuje uslijed procesa vokalizacije - „davanja glasa“ glavnome liku i pripovjedaču romana. ${ }^{29}$ Budući da je roman ispripovijedan u prvome licu, metafore smrti u djelu vrše značajnu funkciju pri profiliranju lika Ivana Galeba. One odražavaju njegov odnos prema smrti na eksplicitnoj i implicitnoj razini. Tako, primjerice, izostanak

$\overline{26}$ S obzirom za žanrovsku pripadnost i obilježja djela te u skladu s prethodno predstavljenim tumačenjem Lakoffa i Turnera.

27 Usp. J. Marin-Arrese, „To Die, to Sleep“.

28 U romanu se ipak pojavljuje implicitna poredba smrti i spavanja, npr. „Na takav prizor uvijek mi se navraća pomisao da bi lica spavajućih, iz pijeteta, trebalo samilosno zastrijeti maramom, kao lica umrlih." (27)

29 Ovaj termin u književnoj pragmatici podrazumijeva „davanje glasa“ liku u književnom djelu. Vokalizacija je iznimno složen proces zbog toga što on ne podrazumijeva samo doslovno „davanje riječi“ liku, već i otkrivanje njegove perspektive iz koje pristupa drugim likovima i svojoj okolini - prenošenje čitatelju njegova pogleda na svijet. Usp. Jakob Mey, Concise Encyclopedia of Pragmatics, Oxford 2009., 553. 
metafora zasnovanih na kršćanskim uvjerenjima te načelno eufemističkih metafora (inače dominantnih u svakodnevnoj komunikaciji) posredno otkriva Galebov svjetonazor, posebice stav i odnos prema smrti. Smrt za njega nije tabu-tema - štoviše, smrt je njegova opsesija. $S$ obzirom na to da se u romanu otvoreno suočava sa smrću, Galeb s razlogom ne poseže za eufemističkim metaforama, već za onima koje više ili manje eksplicitno odražavanju njegovo poimanje smrti - kao nemilosrdnog neprijatelja, kao vlažnog i mračnog prostora, izvora neugodnih mirisa, kao bolesti i neizbježnog kraja. Drugim riječima, izbor metafora s polaznom domenom smrti kojima se pripovjedač služi igra značajnu ulogu u procesu posredne vokalizacije njegova straha. Šire promatrano, metaforika smrti u romanu sudjeluje u konceptualizaciji Galebova svijeta, a time i svijeta djela u cjelini. Nadalje, za interpretaciju Proljeća Ivana Galeba značajan je i podatak da najzastupljenija pojmovna metafora smrti u romanu glasi SMRT je žIvo BIĆE, posebice u užem smislu ljudskog bića. Njezinom čestom aktualizacijom motiv smrti zadobiva svojevrsnu funkciju lika, Galebova suparnika (sMrT je NEPRIJATELJ). Rezultati provedene analize pokazali su da metafore - kako nekonvencionalne tako i one konvencionalne - vrše značajne funkcije u procesu konstituiranja romana na više razina.

Pitanje odnosa između pojmovne metafore i metafore kao stilske figure i danas je predmet rasprava i prijepora među teoretičarima književnosti i lingvistima. Rezultati analize metaforike smrti u Desničinu romanu potvrdili su njihovu izravnu povezanost, ali i određena odstupanja. Analizom pojmovne metafore u Proljećima Ivana Galeba željelo se ukazati na mogućnosti i specifične uvide koje kognitivna i pragmatička (lingvistička) perspektiva mogu donijeti proučavanju prozne metafore te tumačenju književnoga teksta. Također se željelo ukazati na ograničenja do kojih dolazi uslijed strogog razgraničavanja poetskog i nepoetskog jezika, a time i književnoteorijskog i lingvističkog pristupa metafori. Ovim se radom težilo dokazati da se njihovim udruživanjem mogu steći novi, drugačiji uvidi koji mogu poslužiti kao polazište ili doprinos daljnjim interpretacijama.

\section{$\cos$}

\section{Literatura}

Krešimir BAGIĆ, Rječnik stilskih figura, Zagreb 2012.

Vladimir Biti, Pojmovnik suvremene književne teorije, Zagreb 1997.

Eliecer Crespo Fernandéz, „The Language of Death: Euphemism and Conceptual Metaphorization in Victorian Obituaries", SKY Journal of Linguistics, 19/2006., 101-130.

Vladan Desnica, Proljeća Ivana Galeba, Varaždin 2005.

Vladan Desnica, Proljeća Ivana Galeba, Beograd 2010. (https://gimnazijadg.files.wordpress. com/2012/04/vladan-desnica-proljeca-ivana-galeba.pdf)

Rajna DraGićEvić, Leksikologija srpskog jezika, Beograd 2007.

Elena FaUr, The Metaphors for Death and the Death of Conceptual Metaphors in Poetry. An Analysis Based on Emily Dickinson's Poem „Because I Could Not Stop For Death“" (http://www.dacoromania.inst-puscariu.ro)

Cristina Flores Moreno, „Time, Life and Death Metaphors in Shakespeare's Sonnets: The Lakoffian Approach to Poetic Metaphors", RESLA, 13/1998. - 1999., 287-304.

Duška Klikovac, Metafore u mišljenju i jeziku, Beograd 2004. 
George Lakoff - Mark Johnson, Metaphors we live by, Chicago 1980.

George Lakoff - Mark Turner, More Than Cool Reason. A Field Guide to Poetic Metaphor, Chicago 1989.

Juane I. Marin-Arrese, „To Die, to Sleep: A Cotrastive Study of Metaphors for Death and Dying in English and Spanish", Language Sciences, 18/1996., br. 1-2, 37-52.

Zenaida Meco, „Konceptualna analiza smrti na primjeru pjesme Modra rijeka Maka Dizdara“, Zbornik radova Pedagoškog fakulteta u Zenici, 6/2008., 261-267.

Jakob Mer, Concise Encyclopedia of Pragmatics, Oxford 2009.

Maja Opašıć - Maja Gregorović, „Smrt u hrvatskoj frazeologiji“, Croatica et Slavica Iadertina, 6/2010., 55-72.

Elena Semino - Gerard Steen, „Metaphor in Literature“, The Cambridge handbook of metaphor and thought, Cambridge 2008., 232-246.

Milivoj Solar, Teorija književnosti sa rječnikom književnoga nazivlja, Beograd 2012.

Ante Stamać, Teorija metafore, Zagreb 1983.

Mateusz-Milan Stanojević, Konceptualna metafora: temeljni pojmovi, teorijski pristupi i metode, Zagreb 2013.

\section{Conceptual METAPHOR AND THE CONCEPTUALizaTion OF Death in Vladan Desnica's PROLJEĆa IVANA Galeba}

While in literary theory metaphor is defined as a figure of speech, cognitive semantics views it as the mental mechanism through which humans understand and organize their perception of reality. The conceptual metaphor theory is based on the hypothesis that simple and concrete phenomena from the world around us are experienced directly, while more abstract and complex ones are grasped via more familiar, basic experiences. Thus, cognitive semantics defines meaning as the subjective conceptualization of reality and considers language the key indicator of the way we think. This paper deals with the ways in which the complex and abstract idea of death is conceptualized in Vladan Desnica's novel Proljeća Ivana Galeba (The Springs of Ivan Galeb), where it is one of the central motifs. The insights gained from this analysis are then compared to the results of a study of conceptual metaphors of death in ordinary, non-poetic language. The relationship between lexcial (non-poetic) metaphor and metaphor as a figure of speech (poetic metaphor) is also analyzed, as is the relationship between poetic and ordinary language and the boundaries between them. The paper contains four chapters. The introductory chapter provides a short overview of the literary and linguistic theories of metaphor and divides them into two groups: those which stress the differences between metaphors as tropes (poetic metaphors) and lexical (non-poetic) metaphors, and those which stress the correlation and interdependence between the two types of metaphors. The second chapter provides a short introduction to the cognitive approach to metaphor as a mental mechanism through which humans conceptualize reality, which is reflected in language - in its poetic function as well the non-poetic. The third chapter lists the most commonly used conventional conceptual metaphors of death, while the fourth chapter compares them to those used in the novel Proljeća Ivana Galeba. The final chapter presents the results of the study, with a particular focus on the types and functions of the conceptual metaphors of death in Desnica's novel.

Key words: poetic metaphor, conceptual metaphor, conceptual analysis, Vladan Desnica, Proljeća Ivana Galeba (The Springs of Ivan Galeb) 
